\title{
APPLYING AHP TO THE SELECTION OF SUPPLIERS OF MARKETING MATERIALS TO A LARGE BRAZILIAN COMPANY IN THE FOOD AND BEVERAGE INDUSTRY
}

\author{
Denise Lindstrom Bandeira** \\ School of Management \\ Federal University of Rio Grande do Sul \\ Porto Alegre, RS, Brazil \\ E-mail: dlbandeira@ea.ufrgs.br \\ João Luiz Becker \\ School of Management \\ Federal University of Rio Grande do Sul \\ Porto Alegre, RS, Brazil \\ E-mail: jlbecker@ea.ufrgs.br \\ Helena Dantas Waquil \\ School of Management \\ Federal University of Rio Grande do Sul \\ Porto Alegre, RS, Brazil \\ E-mail: helena_waquil@hotmail.com
}

\begin{abstract}
Supplier selection is a key decision in the procurement and purchasing processes. Both the choice of criteria and the evaluation of possible alternatives are critical steps in this decision-making. This paper presents an application of the Analytic Hierarchic Process (AHP) technique to the process of selecting a supplier of marketing materials to a large Brazilian company in the food and beverage industry. Six criteria were identified as decisive for selecting suppliers of materials used in marketing campaigns. These criteria were grouped according to their relevance by a group of executives with the company, labeled (1) determining criteria (quality, timing and cost), (2) distinguishing criteria (service and innovation) and (3) adjustment criterion (quantity). Suppliers can perform differently in each criterion (or subcriterion) so the choice among alternatives (potential suppliers) was supported by the AHP as it made possible the crosscomparison of both qualitative and quantitative criteria. This was the main benefit reported by the executives, who were very pleased with the results obtained, especially the hierarchical classification of criteria and alternatives as it helped to ensure them that the potential suppliers' performance was evaluated and fully compared in each criterion.
\end{abstract}

Keywords: decision making, supplier selection, purchasing process

\footnotetext{
${ }^{*}$ Corresponding author

- The authors would like to thank CNPq and CAPES, two Brazilian governmental agencies, for supporting the research on which this work was based.
} 


\section{Introduction}

Supplier selection is a key decision in the procurement and purchasing processes. Both the choice of criteria and the evaluation of possible alternatives are critical steps in this decision-making process. This paper offers an application of the Analytic Hierarchic Process (AHP) technique to the process of selecting a supplier of marketing materials to a large Brazilian company in the food and beverage industry.

The study was conducted in a large beverages bottler and distributor in Brazil, which is expanding into the food industry. For confidentiality reasons, it will be referred to in this article as company X. The firm operates in a co-manufacturing system, in which independent business groups called manufacturers or bottlers are authorized by a leader and relate through a framework of exchange, in which mutual dependence and subordination are present. The co-manufacturers buy the beverage concentrate (drink syrup) from the leader company and produce the final product by observing strict quality standards required worldwide. In addition to carrying out most of the production process, the bottlers are also responsible for distribution in the retail outlets that sell the final products.

One factor that differentiates the operation of company $\mathrm{X}$ from its competitors is the success of marketing knowledge and applications of the major brands that are known and well accepted worldwide by consumers in the soft drinks market. The strategies are thought out by both parties in the system and benefit both the leader company and the co-manufacturers. In the case in point, the purchase of marketing materials and merchandising, and the process of selecting the vendor is a function of the co-manufacturer, which is responsible for the buying process as a whole, including the final decision. These materials have a direct impact on the final consumers, because they are associated with the brand and serve to sparkle the desire to purchase the product. The application described here deals more specifically with the purchase of banners to advertise a promotional activity targeted at small clients of company $\mathrm{X}$, such as convenience stores, grocery stores, bakeries, and corner stores. The final decision was based on the comparison of the performance criteria of three short listed vendors.

Following a thorough literature survey, six criteria were identified as being decisive for selecting suppliers of materials used in marketing campaigns. These criteria were grouped according to their relevance by a group of executives from company X, labeled (1) determining criteria (quality, timing and cost), (2) distinguishing criteria (service and innovation) and (3) adjustment criteria (quantity). Suppliers can perform differently in each criterion (or subcriterion) so the choice from among alternatives (potential suppliers) was supported by the AHP as it facilitated cross-comparison of both qualitative and quantitative criteria.

\section{Development of the model}

The criteria identified as decisive for selecting suppliers of materials used in marketing campaigns are represented in Figure 1.

At the first level, the goal is defined by the question: Which supplier of materials used in marketing campaigns should be chosen? The criteria and subcriteria were obtained interactively, in successive meetings with a group of six experts from the company $\mathrm{X}$ who are directly involved in the process of purchasing marketing and merchandising materials. The experts are representatives of the three departments involved in making the decision, namely (1) trade marketing department, responsible for purchasing materials for the promotional campaigns and for points of sales; (2) communications department, responsible for purchasing materials for the setting of promotional meetings, and (3) supply department, responsible for purchasing all materials and providing support to the other departments. The criteria were first defined based on a literature survey (Nelson, Moody, and Stegner, 2001; Leenders, Fearon, Flynn, and Johnson, 2002; Bruel, 2007; Cousins, Lamming, Lawson, and Squire, 2008), then analyzed individually by the experts, and then presented in an open discussion group meeting about their relevance to the final decision. As 
Saaty (2007) points out, the process of considering and choosing each criterion is not a mathematical mechanism.

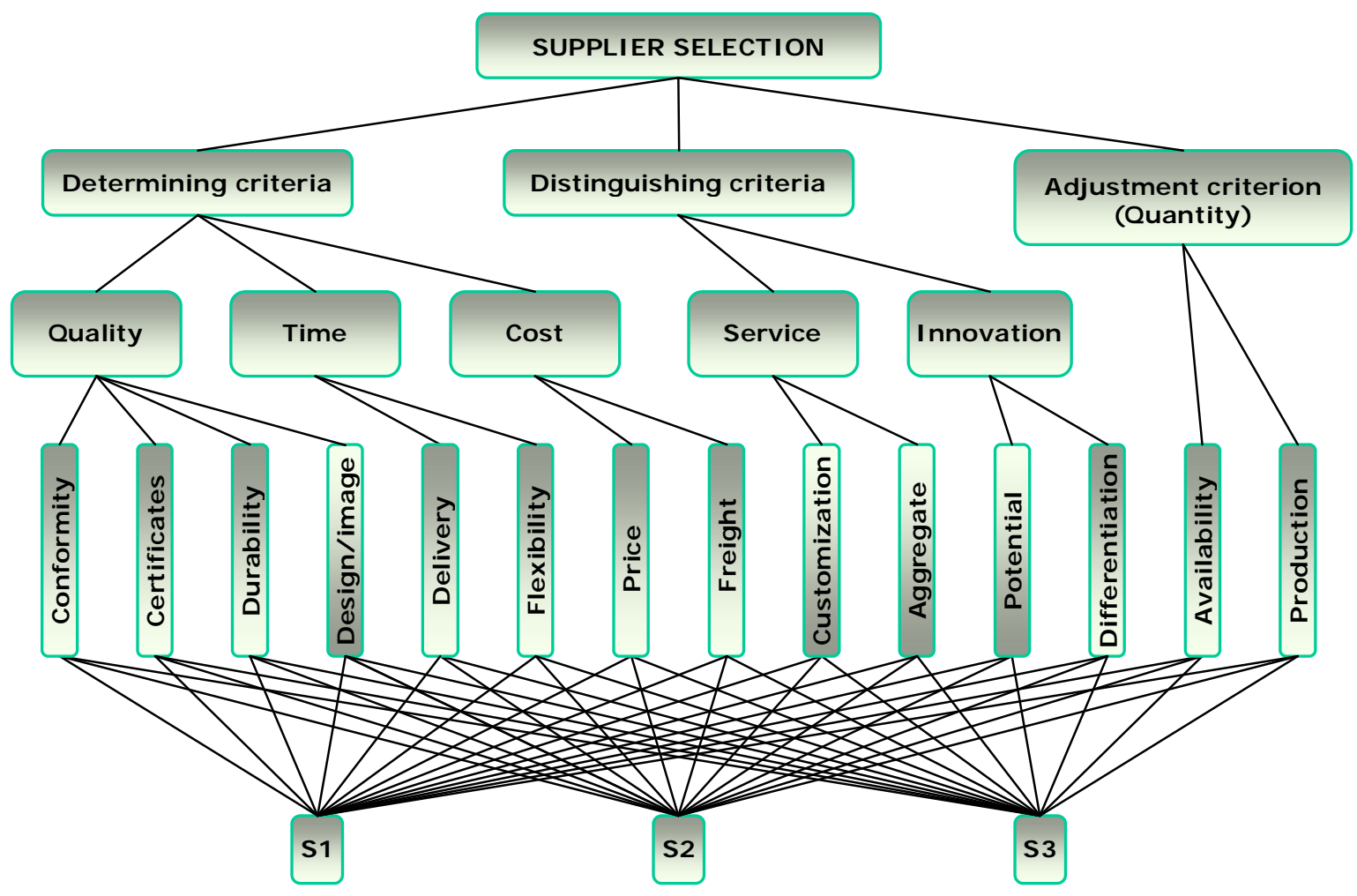

Figure 1. Hierarchical structure for the supplier selection problem.

The six criteria identified as important for selecting suppliers of materials used in marketing campaigns were further broken down into subcriteria. Quality is composed of four subcriteria (conformity, certificates, durability, and design/image). Timing is composed of two subcriteria (delivery and flexibility). Cost is composed of two subcriteria (price and freight). Service is composed of two subcriteria (degree of customization and aggregate value). Innovation is composed of two subcriteria (innovation potential and degree of differentiation). And quantity is composed of two subcriteria (availability and production capacity). The operational definitions of the subcriteria in the fourth level are explained below.

- Conformity: degree to which the product satisfy the required specifications previously established by company X;

- Certificates: number and value of quality certificates the supplier possesses;

- Durability: expected life time of the product;

- Design/image: overall appearance of the proposed layout and print quality;

- Delivery: confidence of on time delivery in all different points of supply;

- Flexibility: capacity to accept changes in product quantity or in its specifications;

- Price: unit price of the product;

- Freight: refers to the monetary value of the delivery in all points of supply;

- Degree of customization: customized services embedded in the product beyond what was specified by company $\mathrm{X}$;

- Aggregate value: expected net benefits the product will generate to company X;

- Innovation potential: perceived interest and efforts made by the vendor to innovate; 
- Degree of differentiation: refers to the distinctiveness of the product or service;

- Availability: immediacy of delivery;

- Production capacity: maximum daily production.

Using the hierarchical structure, pairwise comparison between the objects from each hierarchical level in relation to each object in the hierarchical level immediately above were independently produced by two executives and later incorporated into single matrices depicting the average scores. After analyzing the consistency ratios, the relative weights were distributed as shown in Table 1.

Table 1. Relative priority and CRs of the criteria and subcriteria.

\begin{tabular}{|c|c|c|c|c|}
\hline Criteria & Subcriteria level 1 & Subcriteria level 2 & $\begin{array}{l}\text { Relative } \\
\text { priority }\end{array}$ & $\mathbf{C R}$ \\
\hline \multirow[t]{11}{*}{ Determining } & \multirow{5}{*}{ Quality } & & 0.182 & 0.053 \\
\hline & & Conformity & 0.558 & 0.063 \\
\hline & & Certificates & 0.046 & 0.046 \\
\hline & & Durability & 0.299 & 0.033 \\
\hline & & Design/image & 0.097 & 0.059 \\
\hline & \multirow[t]{3}{*}{ Time } & & 0.748 & 0.060 \\
\hline & & Delivery & 0.600 & 0.063 \\
\hline & & Flexibility & 0.400 & 0.056 \\
\hline & \multirow[t]{3}{*}{ Cost } & & 0.070 & 0.066 \\
\hline & & Price & 0.475 & 0.077 \\
\hline & & Freight & 0.525 & 0.056 \\
\hline \multirow[t]{6}{*}{ Distinguished } & \multirow[t]{3}{*}{ Service } & & 0.500 & 0.038 \\
\hline & & Degree of customization & 0.400 & 0.046 \\
\hline & & Aggregate value & 0.600 & 0.033 \\
\hline & \multirow[t]{3}{*}{ Innovation } & & 0.500 & $\mathbf{0 . 0 3 4}$ \\
\hline & & Potential & 0.300 & 0.081 \\
\hline & & Degree of differentiation & 0.700 & 0.014 \\
\hline \multirow[t]{2}{*}{ Adjustable } & \multirow[t]{2}{*}{ Quantity } & Availability & 0.400 & 0.063 \\
\hline & & Production capacity & 0.600 & 0.069 \\
\hline
\end{tabular}

The final ranking of the suppliers is presented in Table 2 .

Table 2. Composite priorities of the alternatives.

\begin{tabular}{|c|c|c|c|c|}
\hline & $\begin{array}{c}\text { Determining } \\
\text { criteria } \\
(\mathbf{0 . 7 0 0 )}\end{array}$ & $\begin{array}{c}\text { Distinguishing } \\
\text { criteria } \\
(\mathbf{0 . 2 0 0})\end{array}$ & $\begin{array}{c}\text { Adjustment } \\
\text { criterion } \\
(\mathbf{0 . 1 0 0 )}\end{array}$ & Composite \\
\hline S1 & 0.720 & 0.208 & 0.776 & $\mathbf{0 . 6 2 3}$ \\
\hline S2 & 0.192 & 0.678 & 0.156 & $\mathbf{0 . 2 8 5}$ \\
\hline S3 & 0.088 & 0.114 & 0.069 & $\mathbf{0 . 0 9 1}$ \\
\hline CR & $\mathbf{0 . 0 5 9}$ & $\mathbf{0 . 0 2 4}$ & $\mathbf{0 . 0 6 7}$ & $\mathbf{0 . 0 5 3}$ \\
\hline
\end{tabular}




\section{Analysis}

The ranking of the alternatives obtained through the application of the AHP technique, reflecting the choice of the sales team, shows that the first priority should be to choose supplier S1, followed by suppliers $\mathrm{S} 2$ and $\mathrm{S} 3$.

A comparison of the relative weights of the general criteria clearly demonstrates that the company is focused on quality, time and cost, not surprisingly labeled determining criteria. Among these, time emerges as the most important criterion. This is easily explained by the fact that the product and related services the supplier will provide are related with marketing campaigns, which are dynamic in essence (Cousins, 2008). In this sense, timeliness is crucial in order not to bear damage to the action, the campaign, or the event. The amount of time between the purchase of materials and the launching of the campaign is very short, thus squeezing due dates.

The model proved to be practical and efficient in the context of the procurement of marketing materials and merchandising, as it led to choices that were justified by the performance of each supplier within the criteria. In business, it has become increasingly important to justify choices in order to seek to depersonalize the decision. For company X, this was the biggest advantage of the model as it allowed choices to be made on more rational and objectively justified bases.

The major difficulty in developing the method was precisely that of quantifying factors previously treated as purely qualitative. For this reason, the model suffered some influence from the subjective condition of evaluating performance both when establishing the weight attributed to the importance of each criterion and when defining the comparative scale for the score of each supplier within the specifications.

Using scales was the means found to transform qualitative values into measurable definitions, thus allowing the quantitative comparison of values. As a result, it was possible to create a choice ranking for the decision using the total score of each supplier. The subjectivity present in the score for the performance of each supplier in each criterion constitutes a limitation to the model, so emphasized in the work of Simon (1960) with regard to the limited rationality of human decision making.

At first glance the proposals examined were very similar, which made the decision difficult without the model. In similar situations in the past the decision makers felt unsecure and tended to always choose the same suppliers without assessing all the criteria in the other proposals. It can be seen from the analysis that the greater the similarity of the proposals, the greater the difficulty in the decision and therefore the greater the importance of the model in showing the best proposals.

The qualitative part of the decision would mainly involve negotiation and reliability, factors that depend on the strategies and skills of all the parties involved and which by its turn depend on the relationship between them. Every selection procedure has to be exposed to and negotiated with all the potential suppliers. Normally, it is in the interest of the suppliers to understand why their proposal was not selected in order to keep their chances in future selections in relation to other competitors. This should be done with all the interested parties who wish to continue to participate in future processes. Using the AHP technique allows the criteria to be clearly exposed to the competitors.

This study highlights the importance of creating a logical and reasoned process to select suppliers. The simple collection of quotations from some suppliers in order to compare prices, a method still widely used in many firms, is incomplete, insufficient and unable to provide the buyer with a safe and satisfactory decision. Other criteria should be considered when choosing a supplier, and their particular elements and relevance depend on the type of purchase involved. Using the AHP technique, the choices are not obtained through affinity or preference and the proposals are considered and compared, formalizing the buy- 
ing process and providing greater credibility in the choice. This would be a great improvement for company $\mathrm{X}$, which currently tends towards conservatism in using the same suppliers with whom they have worked before, even though there may be better proposals on offer. With regard to the participants in this decision, despite the dynamism which they work when dealing with numerous demands besides those related to the purchase of marketing materials and merchandising, the AHP technique was understood and approved with satisfaction, which led the model to achieve the desired results.

Company $\mathrm{X}$ has a conservative profile with a certain lack of confidence regarding the diversification of the supplier portfolio. However, by using the decision support model the company would be able to abandon its 'convenient situation' and expand its range of suppliers, as it is able to evaluate them without prejudice to the current state and without making the selection process more risky for the company. The suggested decision support model applying the AHP technique constitutes an improvement to the purchasing process in company $\mathrm{X}$. The purchase that was previously made manually, based solely on delivery and unit price criteria, is now better defined and analyzed through parameters checked with the experts, improving the process and providing a better outcome.

The model can generate a better competitive position for the company through fair negotiation and greater credibility, which are purchasing aims and, if well established, can create advantages in the choice of suppliers in relation to competitors in the market. The negotiation between the parties is another theme that permeates the focus of this study and can be extended in future research. Finally, to cope with the uncertainty and new trends prevailing in today's markets, it is critical that the company X develops a holistic view of the purchasing process. This ability will allow the use of all the information available in the process for convergence in the best value for the company, i.e. the best choice.

\section{REFERENCES}

Bruel, O. (2007). Management des achats - décisions stratégiques, structurelles et opérationnelles. Paris: Economica.

Cousins, P., Lamming, R., Lawson, B., \& Squire, B. (2008). Strategic supply management: Principles theories and practice. London: Prentice Hall Financial Times.

Leenders, M.R., Fearon, H.E, Flynn, A.E., \& Johnson, P.F. (2002). Purchasing \& supply management. New York: McGraw-Hill.

Nelson, D., Moody, P.E., \& Stegner, J. (2001). The purchasing machine - how the top ten companies use best practices to manage their supply chains. New York: Simon and Schuster.

Saaty, T.L. (2007). Multi-decisions decision-making: In addition to wheeling and dealing, our national political bodies need a formal approach for prioritization. Mathematical and Computer Modeling, 46 (78), 1001-1016.

Simon, H.A. (1960). The new science of management decision. New York: Harper. 